American Journal of Pharmaceutical Education 2019; 83 (7) Article 6994.

\title{
RESEARCH
}

\section{Current Status of Immunology Education in US Schools and Colleges of Pharmacy}

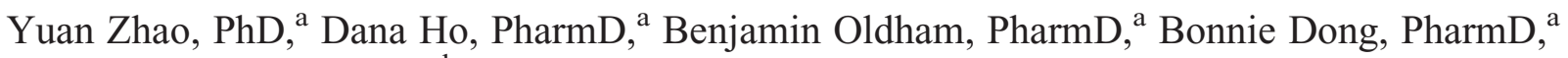 \\ Daniel Malcom, PharmD ${ }^{\mathrm{a}, \mathrm{b}}$ \\ ${ }^{a}$ Sullivan University College of Pharmacy, Louisville, Kentucky \\ ${ }^{\mathrm{b}}$ Associate Editor, American Journal of Pharmaceutical Education, Arlington, Virginia \\ Submitted February 2, 2018; accepted June 17, 2018; published September 2019.
}

\begin{abstract}
Objective. To determine the extent of immunology education in US Doctor of Pharmacy (PharmD) programs.

Methods. Curricular information on immunology education was collected from the web pages of US PharmD programs $(\mathrm{N}=142)$. The data were sorted, comparisons were made, and trends were identified. Results. Of 142 PharmD programs studied, 100\% posted curriculum information on their websites. Among them, 73 programs (51.4\%) had a dedicated immunology course in their curriculum, either as an independent course or a course combined with another subject. Most immunology education was offered in the first professional year $(72.5 \%)$. Of the programs that offered immunology as an independent course, the number of semester hours dedicated to the course varied from 1.5 to 3.5 $($ median $=3$, mode $=3$, mean $=2.7$ ). More three-year programs offered immunology as a core component in the didactic curriculum than did four-year programs $(64.7 \%$ vs $49.6 \%)$. Similarly, more private programs offered immunology than did public programs (64\% vs $37.3 \%)$.

Conclusion. Immunology education in US schools and colleges of pharmacy lacks consensus. Not all PharmD programs indicated they offered specific, focused immunology education in their curricula. There were also variations in the placement of immunology content within the curriculum among programs offering specific immunology course(s). Lastly, there was discrepancy in the allocation of credit hours to the immunology courses. Continued discussion on standardization of immunology education across US pharmacy schools is recommended.
\end{abstract}

Keywords: immunology, pharmacy education, curriculum

\section{INTRODUCTION}

Immunology is a fundamental discipline of medicine that studies the mechanisms of how the body defends itself against foreign entities at a cellular and molecular level, as well as involvement of the immune system in the pathophysiology of various disease states. ${ }^{1}$ Through advancements in technology, imaging, and drug development, immunology is used in medical specialty fields such as oncology, transplantation, rheumatology, neurology, infectious disease, and others. ${ }^{2-8}$ An understanding of the core concepts of immunology is increasing in importance, and it is also used in the diagnosis of several diseases (eg, tuberculin skin testing, rapid diagnostic test-

Corresponding Author: Yuan Zhao, Sam Houston State University, Proposed College of Osteopathic Medicine, Box 2303, Huntsville, TX 77341. Tel: 9362942392. E-mail: yuan.zhao@shsu.edu

Note: At the time of the study, Yuan Zhao was affiliated with Sullivan University College of Pharmacy. ing). Examples of the contributions of immunology to the medical field include development and use of vaccinations and the growing number of monoclonal antibodies used to treat a variety of disease states such as cancer and inflammatory disorders. ${ }^{3-8}$ Pharmacists pursuing training in or practicing in highly specialized areas such as oncology require an even deeper understanding of immunotherapy to provide the highest level of patient care. For example, a recent advancement in immunotherapy is chimeric antigen receptor (CAR) $\mathrm{T}$ therapy, in which the patient's own $\mathrm{T}$ lymphocytes are collected and genetically modified before transfusing them back into the patient in order to fight off malignant tumors. ${ }^{6}$ No matter the area of practice, an understanding of the immune system is critical to fully appreciate the purpose and the mechanism of these drugs and therapies.

Given the large and increasingly important role of immunology in medical and pharmacy practice, immunology is among the topics required to be taught in 


\section{American Journal of Pharmaceutical Education 2019; 83 (7) Article 6994.}

pharmacy curricula. The Accreditation Council for Pharmacy Education (ACPE) Standards 2016 mandate (through Appendix 1) that pharmacy programs should ensure students are able to fully understand human immunity and immune response, principles of antigen-antibody relationships, the molecular aspects of immune response, as well as the genetic basis for antibody synthesis, development, function, and immunopathology. ${ }^{9}$ Notably, Appendix 1 is silent as to the weight (often reflected in time allocated) that should be devoted to each topic on the list, and only states that the topics are viewed as "central" to a high-quality pharmacy education. ${ }^{9}$

The Pharmacy Curriculum Outcomes Assessment (PCOA), which is conducted by the National Association of Boards of Pharmacy (NABP), is designed to provide an external and objective measure of student performance in US pharmacy curricula. The PCOA lists immunology as a subtopic of the basic medical sciences domain in which pharmacy students are expected to show proficiency. ${ }^{10}$ The current PCOA content areas and subtopics are largely based on the results from the 2015 NABP US Schools and Colleges of Pharmacy Curricular Survey, which ranked immunology 20 out of 30 topics in order of overall importance to the curriculum. ${ }^{11}$ Of the 200 questions on the PCOA, only four are mapped to immunology. ${ }^{12}$ This equates to roughly $2 \%$ of the total PCOA content.

Despite its required nature in pharmacy curricula, no review to date has explored the manner in which immunological concepts are integrated within pharmacy education. While immunology has been evaluated (as a part of a larger review) in terms of its importance as a prerequisite prior to entering pharmacy school, ${ }^{13}$ no study has been published detailing how pharmacy programs allocate didactic curricular time to immunology. Thus, the goal of this study was to summarize available information on the manner and degree to which immunology is included in curricula of US Doctor of Pharmacy (PharmD) programs.

\section{METHODS}

One hundred forty-one US schools and colleges of pharmacy recognized as regular or associate members of the American Association of Colleges of Pharmacy (AACP) were included in the study. ${ }^{14}$ All of these institutions offered a PharmD in their professional pharmacy programs and were either fully accredited, a candidate for accreditation, or had pre-candidate status from ACPE. ${ }^{15}$ For analysis purposes, Lake Erie College of Osteopathic Medicine (LECOM) was counted twice as it had both a three-year and a four-year PharmD track available (with different curricula), bringing the total number of programs studied to 142 .
The website of each pharmacy school and college was examined in October 2017 to determine the presence of curriculum information. If applicable, the student handbook containing the curriculum was explored. To account for variable terminology, key words such as "immunology," "immunity," "immune," and "immune-" were searched for on the curriculum website or document posted. The following information was gathered: the nature of the immunology course (independent course or combined with another subject) offered as a core (required) component in the curriculum, the length of the program (three years or four years), whether the program was private or public, the timing of the immunology course in the curriculum (first, second, or third professional year), and the number of credit hours dedicated to immunology. Of the 142 programs analyzed, the majority $(n=123 ; 86.7 \%)$ operated under the semester system; thus, we used the semester credit hour measurement for this study. For programs operating in a quarter system, credit hours were converted to semester hours using the following formula: 1.5 quarter credit hours equaled one semester credit hour. For programs operating in a trimester system, credit hours were converted using the following formula: 1.2 trimester credit hour equaled one semester credit hour. Data were recorded and analyzed in Microsoft Excel 2016 (Redmond, WA). As this project involved only review of course information from college or school websites and did not qualify as human subjects research, it did not require institutional review board evaluation.

The AACP's 2017-2018 Pharmacy Prerequisite Information was used to determine how many pharmacy programs either required or conditionally required immunology as a prerequisite. ${ }^{16}$ Conditional requirement was defined as a prerequisite that could be substituted by another course to fulfill a specific requirement. Which courses can substitute for immunology and in what circumstances is decided on a program-by-program basis. Two programs that were included in AACP's list of US schools and colleges of pharmacy at the time of data collection had not been included on AACP's 2017-2018 Pharmacy Prerequisite Information and were therefore not included in this study. These were the University of Texas at El Paso and the Medical College of Wisconsin, both of which were AACP associate institutes and in precandidate status at the time of the study. Lebanese American University was included in the AACP's prerequisite list; however, it was not included in our study because it is located outside of the United States.

\section{RESULTS}

All 142 (100\%) US pharmacy programs had their curriculum posted online in some form, so we were able to include all of the programs in the study. Overall, 73 


\section{American Journal of Pharmaceutical Education 2019; 83 (7) Article 6994.}

(51.4\%) pharmacy programs offered immunology as either an independent course or combined with another subject, while $69(48.6 \%)$ did not have an immunology course specifically listed by name in the curriculum. Data were further evaluated to identify differences between three-year and four-year programs, and between private and public programs. Although there were a smaller number of three-year programs, a higher proportion of these programs offered courses with immunology in the title compared to four-year programs. Among the 17 threeyear programs, $11(64.7 \%)$ offered courses with immunology in the course title versus $62(49.6 \%)$ of 125 four-year programs. Similarly, more private programs offered courses with immunology in the course title compared to public programs. Forty-eight (64\%) of the 75 private programs offered these courses versus $25(37.3 \%)$ of the 67 public programs.

Three $(2.2 \%)$ pharmacy programs required immunology as a specific course prerequisite, and all three of these schools offered a pre-pharmacy program. Two (1.4\%) pharmacy programs conditionally required immunology. These institutions did not offer a pre-pharmacy program, and immunology was listed as an option for part of required biological sciences or advanced sciences courses. The three programs that required immunology as a prerequisite course and also offered it in their prepharmacy curriculum did not have immunology listed as a core course in their professional didactic curriculum. However, the two programs that conditionally required immunology as a prerequisite also did not include immunology in their professional didactic curriculum.

Of the 73 programs that offered immunology in the core didactic curriculum, 39 programs (53.4\%) offered immunology as an independent course, while 34 programs (46.6\%) offered it in a course combined with another subject (Table 1). Table 2 provides a breakdown of the other subjects offered along with immunology. Among the 34 programs offering immunology within a combined course, microbiology was found to be the most common subject with 22 programs $(64.7 \%)$ offering it along with immunology.

Summary data of the specific professional year in which each immunology course was offered is shown in
Table 3. Of all the schools and colleges of pharmacy offering immunology as a core component in the curriculum, 53 programs $(72.5 \%)$ offered it in the first year of the curriculum. Furthermore, 14 programs $(19.2 \%)$ offered the course in the second year of the curriculum. When analyzing independent courses and combined courses, the trend remained applicable. Among the 39 programs offering immunology as an independent course, 28 programs $(71.8 \%)$ offered it in the first professional year, followed by seven programs $(17.9 \%)$ that offered it in the second professional year. Among the 34 programs offering immunology in combined courses, 25 programs $(73.5 \%)$ offered it in the first professional year, while seven programs $(20.6 \%)$ offered it in the second professional year. Overall, most schools offered the course in the first year of their professional program.

Finally, information on credit hours of independent immunology courses was collected and analyzed (presented in Table 4 as semester-hour equivalents). We found that 26 out of 39 programs $(66.7 \%)$ offered immunology as a three-credit hour course, and 11 programs (28.2\%) designated it as a two-credit hour course. The number of semester hours dedicated to the independent immunology course varied from 1.5 to 3.5 (median $=3$, mode $=3$, mean $=2.7$ ). Percentages of credit hours dedicated to an independent immunology course among total didactic curriculum credit hours were calculated for each institution. These percentages ranged from $1.6 \%$ to $3.2 \%$, with an average of $2.7 \%$ of the total didactic curriculum hours.

\section{DISCUSSION}

Immunology is an important and rapidly growing field, with new knowledge and techniques being applied in the treatment of cancer, autoimmune disease, transplantation, allergies, and many other areas. ${ }^{2-8,17,18}$ Given the indispensable role of this field in medicine, healthcare providers must understand immunology to comprehend the mechanisms of immune-related diseases and related therapies. However, there is surprisingly little literature on how immunology is being taught to future healthcare professionals, which makes the value of this study evident.

Table 1. Immunology Education in Curricula of US Doctor of Pharmacy Programs

\begin{tabular}{|c|c|c|c|c|c|}
\hline \multirow[b]{2}{*}{ Course Setting } & \multirow[b]{2}{*}{$\begin{array}{c}\text { Total } \\
\left(\mathrm{N}=142^{\mathrm{a}}\right) \\
\text { n }(\%)\end{array}$} & \multicolumn{2}{|c|}{ Three-year vs Four-year } & \multicolumn{2}{|c|}{ Private vs Public } \\
\hline & & $\begin{array}{c}\text { Three-year } \\
(\mathbf{N}=16) \\
\text { n (\%) }\end{array}$ & $\begin{array}{c}\text { Four-year } \\
(\mathbf{N}=125) \\
\text { n (\%) }\end{array}$ & $\begin{array}{c}\text { Private } \\
(\mathrm{N}=75) \\
n(\%)\end{array}$ & $\begin{array}{c}\text { Public } \\
(\mathrm{N}=67) \\
\text { n (\%) }\end{array}$ \\
\hline Independent course & $39(27.5)$ & $5(29.4)$ & $34(27.2)$ & $26(34.7)$ & $13(19.4)$ \\
\hline Combined with other subject & $34(23.9)$ & $6(35.3)$ & $28(22.4)$ & $22(29.3)$ & $12(17.9)$ \\
\hline
\end{tabular}

${ }^{a}$ LECOM counted twice because it has two programs. The three-year program curriculum has stand-alone immunology course, and the four-year program curriculum has immunology combined with microbiology 


\section{American Journal of Pharmaceutical Education 2019; 83 (7) Article 6994.}

Table 2. Subjects Combined with Immunology in Curriculum of US Doctor of Pharmacy Programs $(\mathrm{N}=34)$

\begin{tabular}{lc}
\hline Subject & n (\%) \\
\hline Microbiology & $22(64.7)$ \\
Biotechnology & $4(11.8)$ \\
Hematology & $4(11.8)$ \\
Pathophysiology & $2(5.9)$ \\
Rheumatology & $1(2.9)$ \\
Toxicology & $1(2.9)$ \\
\hline
\end{tabular}

Based on the curricula posted online, 73 of 142 PharmD programs in the US had immunology listed as either an independent course or combined with another major subject as a core component of the didactic curriculum. We compared three-year programs to four-year programs and private programs to public programs. Interestingly, $64 \%$ of the private programs included in our study had immunology explicitly listed in the curriculum, while only about $37 \%$ of public programs had it listed; similarly, almost $65 \%$ of three-year programs had it listed compared with only about $50 \%$ of four-year programs. Part of this could be explained by a larger proportion of three-year and private programs having started (and their curricula created) within the past 20 years, ${ }^{19}$ thus making it easier for these programs to comply with ACPE standards regarding immunology by having a dedicated course on the topic. Also, many analyses of curricular placement of coursework (ie, first year vs second year) can be confusing when comparing three-year programs to four-year programs because of the accelerated nature of a three-year program. This can be an issue particularly in comparisons of longitudinal program experiences (such as experiential learning or co-curriculum requirement), or even in clinical training such as clinical laboratory or pharmacotherapeutics courses given their likely placement toward the end of didactic training in many programs. Given the substantive majority of programs $(72.5 \%)$ offering immunology in the first year of the program (where basic sciences are likely taught in many curricula, both three- and four-year programs), it was deemed unnecessary to parse those data to separate the three- and four-year programs for this analysis.
While 73 programs were counted as having foundational immunology within their curriculum (by course name), there were 69 programs that did not explicitly have immunology or immunotherapy incorporated into the titles of their core courses. As accreditation standards require every PharmD program to have immunology as a part of their curriculum in some manner, ${ }^{9}$ we can surmise that immunology is being covered in these programs' curricula. In our analysis, however, it was not possible to determine where exactly and in what context this instruction occurs.

As mentioned earlier, four questions on the PCOA ( $2 \%$ of the 200 questions) are directly related to immunology. ${ }^{12}$ Using this methodology, we hypothesized that immunology comprises $2 \%$ of each pharmacy program's overall curriculum. Thus, if a school has a total of 100 (estimated) semester credit hours of didactic courses (excluding experiential), then roughly two credits would be expected to directly relate to immunology. As shown in Table 4, our study found that an average of $2.7 \%$ of total didactic curriculum hours were devoted to immunology, which is in line with what would be expected based on this methodology.

In our study, microbiology was identified as the subject with the greatest number of programs having combined course titles with immunology. Two questions ( $1 \%$ of the 200 total) on the PCOA are directly related to microbiology. ${ }^{12}$ While the proportion of microbiology content in the curricula was not directly assessed in this study, for programs with combined microbiology and immunology courses, using this methodology, approximately $3 \%$ of the total didactic curriculum would be devoted to the combined immunology/microbiology course.

A full analysis of the utility of the PCOA in curricular assessment is outside the scope of this study. However, given both the small number of questions and limited psychometric data available, the percent correct results from individual PCOA subtopics (such as immunology) are likely not useful alone as a gauge of curricular effectiveness. These results can be one component in a comprehensive curricular assessment plan, providing additional objective data that can be tracked over time. As curricula move toward integration and away from distinct course structures, regular quality

Table 3. Year Offering Immunology Education in US Doctor of Pharmacy Programs

\begin{tabular}{lcccc}
\hline \multirow{2}{*}{ Course Setting } & & \multicolumn{2}{c}{ Year Offering Immunology Education (N=73) } \\
n (\%) & & PY2 & PY3 & Not Indicated \\
\hline Independent course & PY1 & $7(9.6)$ & $2.7)$ & $2(2.7)$ \\
Combined with other subject(s) & $28(38.3)$ & $7(9.6)$ & $1(1.4)$ & $1(1.4)$ \\
\hline
\end{tabular}

PY1 = first professional year; PY2= second professional year; PY3=third professional year 


\section{American Journal of Pharmaceutical Education 2019; 83 (7) Article 6994.}

Table 4. Credit Hours ${ }^{\mathrm{a}}$ for Independent Immunology Courses in US Doctor of Pharmacy Programs

\begin{tabular}{|c|c|c|}
\hline $\begin{array}{l}\text { Credit } \\
\text { Hours }\end{array}$ & $\begin{array}{c}\text { Programs } \\
\left(\begin{array}{c}\mathrm{N}=39) \\
\mathrm{n}(\%)\end{array}\right.\end{array}$ & $\begin{array}{c}\text { Average Percentage in Total } \\
\text { Didactic Curriculum Hours } \\
(\%)\end{array}$ \\
\hline 1.5 & $1(2.6)$ & 1.6 \\
\hline 2 & $11(28.2)$ & 1.9 \\
\hline 3 & $26(66.7)$ & 3.0 \\
\hline 3.5 & $1(2.6)$ & 3.2 \\
\hline
\end{tabular}

${ }^{a}$ Credit hours are presented in semester equivalents

assurance of content coverage based on ACPE Standards 2016 Appendix 1 requirements as well as other benchmarks of curricular composition (especially on an aggregate level like in our study) is likely to become more challenging. ${ }^{9}$

One inference that can be drawn from this study is that there is a significant lack of consensus in the academy as to how immunology should be incorporated into pharmacy curricula, given that only a little over half the programs studied have it as a core course (independent or combined with another major subject), and that there is variation in the credit hours allocated to these courses.

There are several important limitations of our study to note. First, our data collection was entirely reliant on the curriculum posted to the website of a school or college of pharmacy being accurate at the time the data were collected. For courses covering immunology combined with another topic, such as microbiology, it was beyond the scope of our study to determine the amount of material dedicated to each respective topic within the course as the syllabi for courses were not easily accessible online. Also, some schools may have immunology content spread throughout the curriculum as embedded topics, such as institutions with fully or partially "integrated" curricula (in which basic sciences are combined with clinical sciences). Our analysis methodology would not have been able to ascertain the individual topics covered within this type of curricular design.

Our study may be useful to curriculum committees in deciding how and when to integrate this subject within their institution's curricula. Further research and consideration is needed to form a consensus and determine the best approach to educating students in this subject area. A follow-up study to this one could involve systematically examining the syllabi of immunology courses from all schools and colleges of pharmacy or surveying curriculum committee chairs or academic affairs personnel as those approaches would provide more information on how exactly programs are teaching immunology in their curricula.

\section{CONCLUSION}

As evidenced by review of pharmacy curricula from program websites, education in immunology is provided in most US schools and colleges of pharmacy. However, the limited amount of time dedicated to teaching immunology (as determined by course titles) could indicate a lack of detailed or thorough exploration of this topic. The varied course settings, credit hours, and placement of immunology in the curriculum also demonstrates inconsistency in its coverage within the PharmD curriculum. Increasing immune-related diseases and drug therapies point to an acute need for immunology education for future pharmacists and other health care professionals. Additional research and consensus within the academy regarding immunology are needed to provide more standardization in this area of pharmacy education.

\section{ACKNOWLEDGMENTS}

The authors thank Heather Garrett, Cassandra Crouch, Tara Nguyen, and Tran Nguyen for their assistance with the project.

\section{REFERENCES}

1. Lee AY, Malau-Aduli BS. Medical students' learning experiences and perceptions of immunology. Internet J Med Educ. 2013;3(1). 2. Tebo AE, Detrick B, Hamilton RG, et al. Clinical laboratory immunology: an indispensable player in laboratory medicine. Am J Clin Pathol. 2014;142(4):437-444.

3. Slifka MK, Amanna I. How advances in immunology provide insight into improving vaccine efficacy. Vaccine. 2014;32(25):29482957.

4. Geskin LJ. Monoclonal antibodies. Dermatol Clin.

2015;33(4):777-786.

5. Conti F, Ceccarelli F, Massaro L, et al. Biological therapies in rheumatic diseases. Clin Ter. 2013;164(5):e413-428.

6. Jackson HJ, Rafiq S, Brentjens RJ. Driving CAR T-cells forward. Nat Rev Clin Oncol. 2016;13(6):370-383.

7. Houot R, Schultz LM, Marabelle A, Kohrt H. T-cell-based immunotherapy: adoptive cell transfer and checkpoint inhibition. Cancer Immunol Res. 2015;3(10):1115-1122.

8. Montalban X, Hauser SL, Kappos L, et al. Ocrelizumab versus placebo in primary progressive multiple sclerosis. $N$ Engl J Med. 2017;376(3):209-220.

9. Accreditation Council for Pharmacy Education. Accreditation Standards and Key Elements for the Professional Program in Pharmacy Leading to the Doctor of Pharmacy Degree. https:// www.acpe-accredit.org/pdf/Standards2016FINAL.pdf. Published 2015. Accessed April 12, 2018.

10. National Association of Boards of Pharmacy. Content Areas of the Pharmacy Curriculum Outcomes Assessment (PCOA). https:// nabp.pharmacy/wp-content/uploads/2016/07/PCOA-Content-Areas9.6.16.pdf. Updated September 2016. Accessed April 12, 2018. 11. National Association of Boards of Pharmacy. The 2015 United States Schools and Colleges of Pharmacy Curricular Survey Summary Report. https:/nabp.pharmacy/wp-content/uploads/2016/ 09/2015-fpgee-and-pcoa-curricular-survey.pdf. Published August 2016. Accessed June 18, 2018. 


\section{American Journal of Pharmaceutical Education 2019; 83 (7) Article 6994.}

12. National Association of Boards of Pharmacy. Pharmacy Curriculum Outcomes Assessment (PCOA) Registration and Administration Guide for Schools and Colleges of Pharmacy. https:// nabp.pharmacy/wp-content/uploads/2018/01/PCOA-RegistrationAdministration-School-Guide-2018.pdf. Updated 2018. Accessed April 12, 2018

13. Gleason BL, Siracuse MV, Moniri NH, Birnie CR, Okamoto CT, Crouch MA. Evolution of preprofessional pharmacy curricula. Am J Pharm Educ. 2013;77(5):Article 95.

14. American Association of Colleges of Pharmacy. AACP Institutional Membership. https://www.aacp.org/article/aacpinstitutional-membership. Accessed April 12, 2018.

15. Pharmacy College Application Service. School Directory PharmCAS. http://www.pharmcas.org/school-directory/\#/pharmd/ general-information. Accessed April 12, 2018.
16. American Association of Colleges of Pharmacy. 2017-18 Pharmacy Pre-Requisite Information. http://www.aacp.org/sites/ default/files/2017-11/pre_reqs-2017-18\%20FINAL.pdf. Accessed April 12, 2018

17. Krensky AM, Azzi JR, Hafler DA A. Immunosuppressants and Tolerogens. In: Laurence L. Brunton, Randa Hilal-Dandan BCK, ed. Goodman \& Gilman's: The Pharmacological Basis of Therapeutics. 13th ed. United States of America: McGraw-Hill Education; 2018. 18. Barnes PJ. Pulmonary Pharmacology. In: Laurence L. Brunton, Randa Hilal-Dandan BCK, ed. Goodman \& Gilman's: The Pharmacological Basis of Therapeutics. 13th ed. The United States of America: McGraw-Hill Education; 2018.

19. Knapp DA, Knapp DE. Attributes of colleges and schools of pharmacy in the United States. Am J Pharm Educ. 2009;73(5):Article 96. 